\title{
Extranasopharyngeal Angiofibroma of Uncinate Process in a Female: A Rare Presentation
}

\author{
${ }^{1}$ Rajesh Pandey, ${ }^{2}$ Pramod K Yadav, ${ }^{3}$ Rajesh Kumar
}

\begin{abstract}
Aim: To present a rare case of extranasopharyngeal angiofibroma (ENA) in a female originating from uncinate process in nasal cavity.

Background: Nasopharyngeal angiofibroma is a rare vascular tumor affecting adolescent male. It is the most common benign tumor of nasopharynx. Angiofibroma located outside the nasopharyngeal area are extremely rare and, consequently, may be misdiagnosed. Unlike nasopharyngeal angiofibroma, symptoms of ENAs are nonspecific and depend on localization and extent of tumor. The occurrence of any nasopharyngeal angiofibroma in females is very rare. Also, ENA has been reported at various subsites in nasal cavity, but origin from uncinate process is not reported in world literature till date. So we are reporting this unique case.
\end{abstract}

Case description: A 40-year-old female presented with intermittent profuse bleeding diagnosed as ENA originating from uncinate process. Tumor is removed completely through lateral rhinotomy approach.

Conclusion: Extranasopharyngeal angiofibroma is a rare tumor but it should be kept in differential diagnosis of vascular tumor of nose and paranasal area. Surgical excision is the treatment of choice for angiofibroma of nose and paranasal sinuses.

Clinical significance: Extranasopharyngeal angiofibromas can originate from various subsites of nasal cavity including uncinate process. Patients affected are older, symptoms develop more quickly, and hypervascularity is less common.

Keywords: Angiofibroma, Extranasopharyngeal angiofibroma, Uncinate process.

How to cite this article: Pandey R, Yadav PK, Kumar R. Extranasopharyngeal Angiofibroma of Uncinate Process in a Female: A Rare Presentation. Clin Rhinol An Int J 2017; 10(3):150-153.

Source of support: Nil

Conflict of interest: None

\section{BACKGROUND}

Nasopharyngeal angiofibromas are relatively rare tumors that represent $0.5 \%$ of all head and neck neoplasms. ${ }^{1}$ The

\footnotetext{
1,3 Senior Resident, ${ }^{2}$ Assistant Professor

${ }^{1-3}$ Department of ENT, Mahamaya Rajkiya Allopathic Medical College, Ambedkar Nagar, Uttar Pradesh, India

Corresponding Author: Rajesh Pandey, Senior Resident Department of ENT, Mahamaya Rajkiya Allopathic Medical College, Ambedkar Nagar, Uttar Pradesh, India, Phone: +919415137061, e-mail: rajeshkgmu04@gmail.com
}

origin of the tumor is from the posterolateral wall of the nasal cavity near the superior margin of the sphenopalatine foramen. ${ }^{2}$ It develops almost exclusively in adolescent males, though there are reports of this tumor being found in children, the elderly, and pregnant women. ${ }^{3}$ The occurrence of any nasopharyngeal angiofibroma in females is very rare.

Angiofibromas that do not originate from the area around the sphenopalatine region are referred to as ENA. The occurrence of ENA is very rare. Clinical manifestations of ENAs are very different than manifestations of nasopharyngeal angiofibroma. We are presenting a unique case of ENA originating from uncinate process in 40-year-old female. Moreover, ENA has been reported at various subsites in nasal cavity but origin from uncinate process is not reported in world literature till date.

\section{CASE REPORTS}

A 40-year-old female presented with history of intermittent profuse bleeding for last 10 years. Each bleeding episode is spontaneous in onset, occurring after interval of 1 to 2 years and profuse in amount. Bleeding used to subside by itself without nasal packing. She had nasal obstruction for last 8 years initially on right side and gradually progressed on both sides, which was not relieved after medication. She noticed a mass in right nasal cavity and subsequently swelling on right side alar crease area for last 2 years. She also had hyposmia and frontal headache on right side. There was no history of fever, neck swelling, trauma, change of vision, hearing impairment, and bruises or bleeding from any other sites. She is a tobacco chewer and has two female children.

General and systemic examination was unremarkable except pallor. On anterior rhinoscopy, a pinkish brown globular solitary smooth mass covered by mucosa occupying right nasal cavity was seen. Probe can be passed all around the mass except laterally and not bleed on probing. Septum was deviated on left side due to mass. No abnormality was found in posterior rhinoscopy in nasopharynx. Other ear, nose, and throat examination was unremarkable.

Noncontrast computed tomography (CT) imaging of nose and paranasal sinuses showed a homogenous soft tissue density in the right nasal cavity without any 


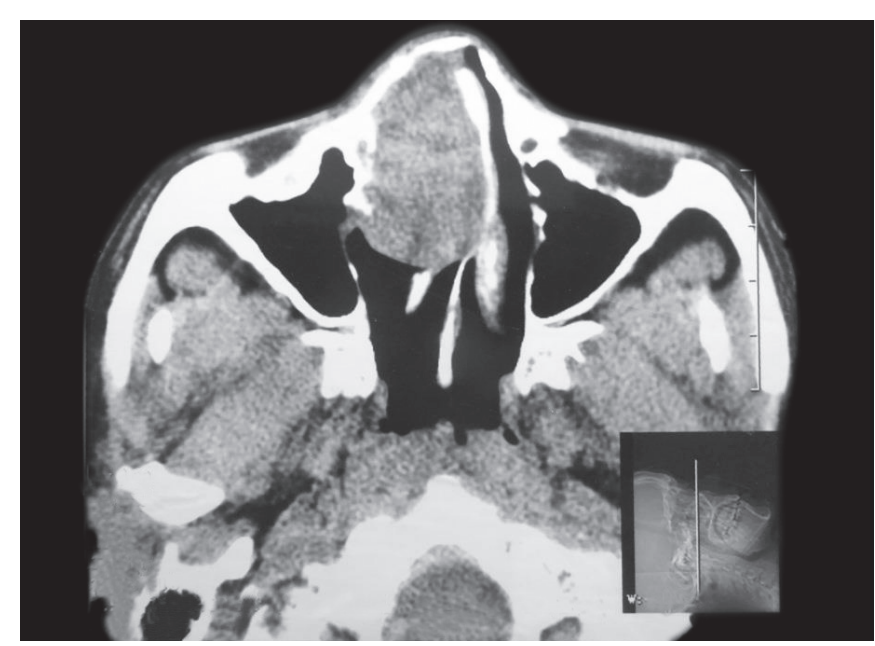

Fig. 1: Axial CT showing soft tissue density in right anterior nasal cavity

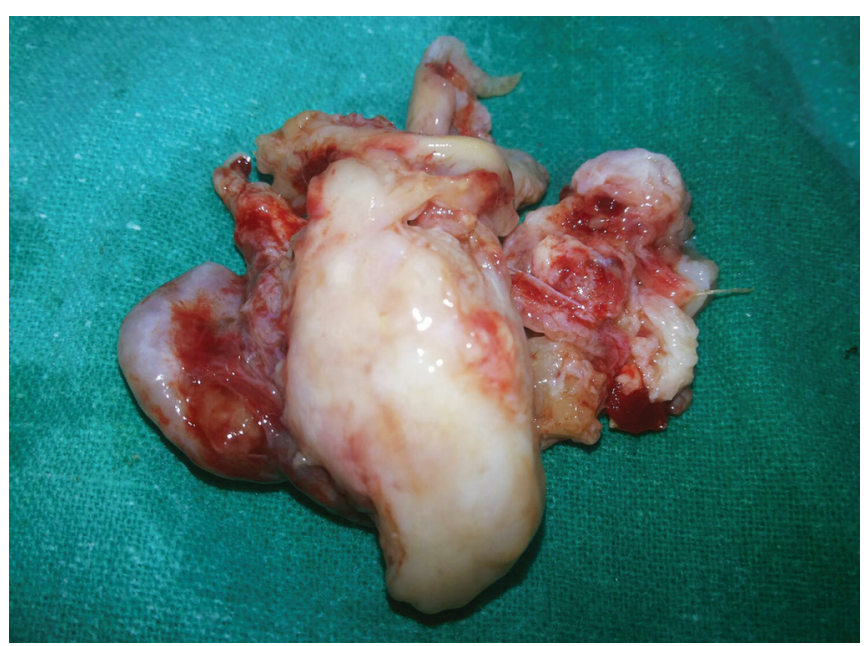

Fig. 3: Pinkish firm smooth mass removed

orbital and intracranial extension. There was no extension beyond anterior nasal cavity into nasopharynx or paranasal sinuses. The sphenopalatine foramen area was normal with no widening. The nasal septum was deviated to left side. There was minimal displacement and erosion of the nasal bone (Figs 1 and 2). Complete blood count showed hemoglobin $7.8 \mathrm{gm} / \mathrm{dL}$ for which 2 units of blood transfused. Coagulation profile was within the normal limit. Other laboratory tests were unremarkable.

Based on these findings, differential diagnosis of hemangioma, angiomatous polyp was made. The result of punch biopsy was reported as capillary hemangioma. Profuse bleeding occurs during biopsy that required anterior nasal packing. The excision of mass was done by lateral rhinotomy approach. A pinkish, firm mass was removed from right nasal cavity in toto (Fig. 3). The origin of tumor was traced which was attached to uncinate process. Intraoperative bleeding was brisk, which stopped after anterior nasal packing. Nasal pack was

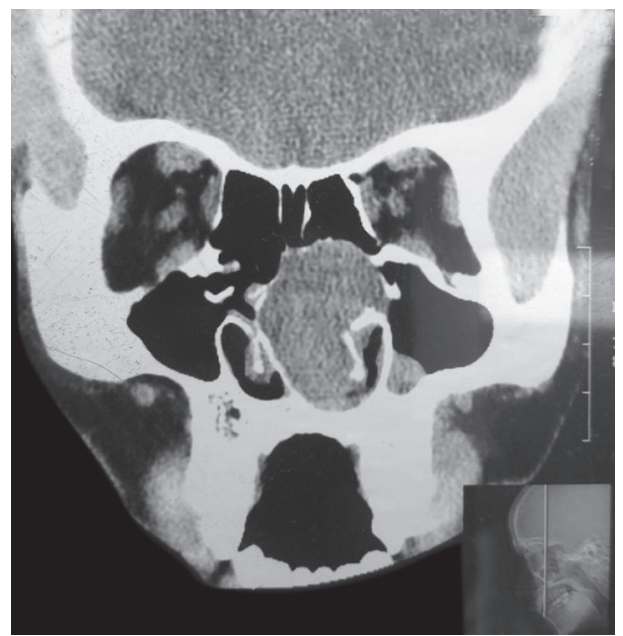

Fig. 2: Coronal CT showing origin of tumor from uncinate process

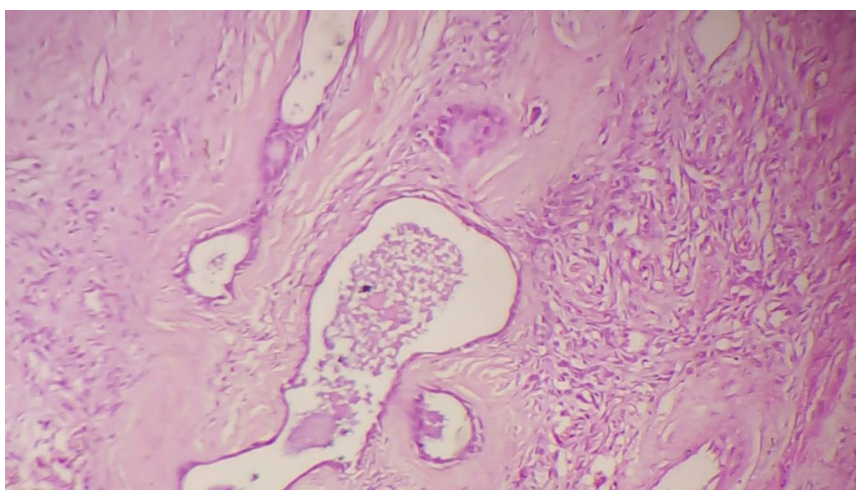

Fig. 4: Histopathological examination showing fibrous stroma with thin-walled blood vessels

removed after 48 hours. Surprisingly, the histopathology was suggestive of angiofibroma which showed loose fibrous stroma with thin-walled scattered blood vessel lined by single layer of endothelial cells and showed an incomplete muscular wall (Figs 4 and 5). The postoperative course was uneventful. A postoperative CT scan showed no residual mass.

\section{DISCUSSION}

Nasopharyngeal angiofibroma is a rare vascular tumor affecting adolescent male. It is the most common benign tumor of nasopharynx. Although histologically benign, it shows locally aggressive growth and spread through natural foramen and fissure. Nasopharyngeal angiofibroma is a challenge for surgeons due to aggressive local growth, skull base location, and risk of profound hemorrhage.

Angiofibromas located outside the nasopharyngeal area are extremely rare and, consequently, may be misdiagnosed. Unlike nasopharyngeal angiofibroma, symptoms of ENAs are nonspecific and depend on localization and extent of tumor. Our patient presented to us with complains of recurrent epistaxis, bilateral 


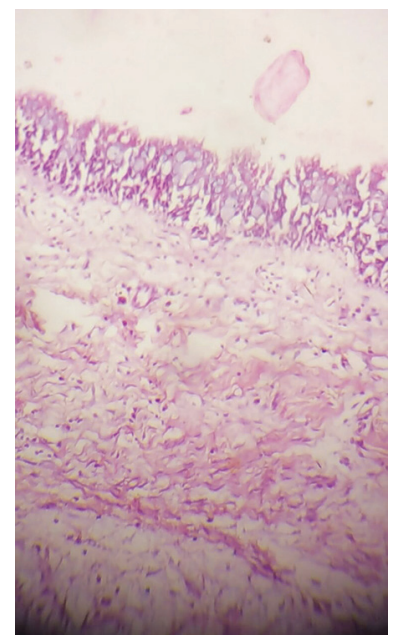

Fig. 5: Histopathological examination showing fibrous stroma with thin-walled blood vessels

nasal obstruction, and headache. Due to limited space for tumor growth, ENAs originating from nasal cavity may be diagnosed early, and ENA is reported more in females when compared with the nasopharyngeal angiofibroma. ${ }^{4}$ But some studies suggest the mean age is 22 years and male to female ratio is $3: 1 .^{5}$

From world literature in 1980 to 2012,39 cases of ENAs originating from nasal cavity were reviewed by Perić et al. ${ }^{6}$ Ten more cases of ENAs were reported in 2013 to 2015. Out of these 49 cases of ENAs originating from nasal cavity, 33 cases were males and 16 females. Our present case of ENA is a 40-year-old female. Classical nasopharyngeal angiofibroma occurs in adolescent males of age between 14 and 25 years.

In a review of literature (1918-2002), Windfuhr and Remmert ${ }^{7}$ found 58 reports of ENAs describing 65 cases. In recent review of literature (2002-2015), 13 more cases of ENAs were reported. The ENAs have been reported to arise from various sites in the head and neck region. The most common ENAs is reported from maxillary sinus ${ }^{8}$ followed by ethmoid labyrinth. On the contrary, Perić et $\mathrm{al}^{6}$ review showed that the most common primary location of nasal angiofibroma is the nasal septum, followed by inferior and middle turbinate. There are also reports of ENAs located in the larynx, sphenoid sinus, cheek, conjunctiva, oropharynx, retromolar area, and tonsils. An isolated case has been published in trachea, lacrimal sac, carotid bifurcation, esophagus, hard palate, facial nerve, external ear, external nose, and infratemporal fossa.

In the present case, we report the very rare case of ENA arising from uncinate process in middle-aged women. To the best of our knowledge, ENA of uncinate process is not reported in world literature so far. So we are reporting this unique case from eastern Uttar Pradesh, India.
Atypical localization of nasal angiofibroma needs a careful differential diagnosis in relation to other vascular lesions, such as lobular capillary hemangioma, sinonasal type hemangiopericytoma, angiomatous polyp, papilloma, antrochoanal polyp, teratoma, encephalocele, dermoid cyst, chordoma, and carcinoma.

Precise histopathological examination of specimen suspected to be angiofibroma is necessary for exact diagnosis. Classical angiofibromas are composed of a dense fibrous stroma with spindled to stellate stromal cell and variably sized thin-walled vascular spaces. Hemangioma generally consists of small amount of fibrous tissue and shows lobulation in different degree. ${ }^{9}$ Biopsy may cause profuse bleeding, as in our case also should be avoided when angiofibroma is suspected. ${ }^{10}$

Extranasopharyngeal angiofibromas are harder to diagnose radiologically due to their various locations. ${ }^{9}$ Computed tomography and magnetic resonance imaging are useful methods to determine localization and spread of ENA. Contrast enhancement of ENAs is usually medium or even nothing due to the frequent poor vascularity of tumor. ${ }^{11}$ Extranasopharyngeal angiofibroma patients affected are older, symptoms develop more quickly, and hypervascularity is less common. ${ }^{12}$

Treatment of ENA is surgical excision, which may need pre-op embolization and special precautions like standby blood for the possibility of severe bleeding. Surgical approach is tailored to the localization and size of tumor. Radiotherapy may be applied for unresectable cases. ${ }^{9}$ Pre-op embolization with the use of endoscope and laser has been reported to achieve better result. ${ }^{13}$ In our case, tumor was removed completely through lateral rhinotomy approach. Preoperative embolization and laser was not used. Intraoperative bleeding was not profuse and stopped after packing. Two units of blood was transfused preoperatively to achieve hemoglobin level of $10 \mathrm{gm} / \mathrm{dL}$.

Nasopharyngeal angiofibroma seems to have poorer prognosis than ENAs due to inadequate surgical exposure; consequently, it may result in a higher recurrence rate. ${ }^{14}$ Most of the recurrences are symptomatic within first year after treatment; beyond 2 years, recurrence is uncommon. However, recurrence was not reported for patients with ENAs. ${ }^{15}$ We have followed our case with repeated endoscopic examination for 1 year and no recurrence was noted.

\section{CONCLUSION}

Extranasopharyngeal angiofibroma is rare tumor but it should be kept as a differential diagnosis of vascular lesions of nose and paranasal sinuses area, especially from capillary hemangiomas and sinonasal-type hemangiopericytoma regardless of the age, sex, or site of lesion. 
The ENA patients affected are older, symptoms develop more quickly, and hypervascularity is less common. Surgical excision is the treatment of choice for angiofibroma of nose and paranasal sinuses.

\section{REFERENCES}

1. Panesar J, Vadgama B, Rogers G, Ramsay AD, Hartley BJ. Juvenile angiofibroma of the maxillary sinus. Rhinology. 2004 Sep;42(3):171-174.

2. Zito J, Fitzpatrick P, Amedee R. Juvenile nasopharyngeal angiofibroma. J La State Med Soc 2001 Aug;153(8):395-398.

3. Gleeson, M. Juvenile angiofibroma. Scott-Brown's otorhinolaryngology, head and neck surgery. Vol. 2. 7th ed. Boca Raton (FL): CRC Press; 2008. p. 2437-2444.

4. Taggarshe D, Quraishi MS, Dugar JM. Inferior turbinate angiofibroma: an atypical presentation. Rhinology 2004 Mar;42(1):45-47.

5. Ungkanont K, Byers RM, Weber RS, Callender DL, Wolf $\mathrm{PF}$, Goepfert H. Juvenile nasopharyngeal angiofibroma: an update of therapeutic management. Head Neck 1996 JanFeb;18(1):60-66.

6. Perić A, Sotirović J, Cerović S, Zivić L. Immunohistochemistry in diagnosis of extranasopharyngeal angiofibroma originating from nasal cavity: case presentation and review of literature. Acta Medica (Hardec Kralove) 2013;56(4):133-141.

7. Windfuhr JP, Remmert S. Extranasopharyngeal angiofibroma: etiology, incidence and management. Acta Otolaryngol 2004 Oct;124(8):880-889.
8. Tasca I, Compadretti GC. Extranasopharyngeal angiofibroma of nasal septum. A controversial entity. Acta Otorhinolaryngol Ital 2008 Dec;28(6):312-314.

9. Pilch, BZ. Soft tissue pathology of head and neck. In: Keel SB, Rosenberg AE, editors. Head and neck surgical pathology. Chapter 10. Philadelphia (PA): Lippincott Williams \& Wilkins; 2001. p. 389-430.

10. Szymańska A,Szymański M,Morshed K, Czekajska-Chehab E, Szczerbo-Trojanowska M. Extranasopharyngeal angiofibroma: clinical and radiological presentation. Eur Arch Otorhinolaryngol $2013 \mathrm{Feb}$;270(2):655-660

11. Harrison DF. The natural history, pathogenesis, and treatment of juvenile angiofibroma. Personal experience with 44 patients. Arch Otolaryngol Head Neck Surg 1987 Sep;113(9): 936-942.

12. Akbas $Y$, Anadolu Y. Extranasopharyngeal angiofibroma of the head and neck in women. Am J Otolaryngol 2003 NovDec;24(6):413-416.

13. Hyun DW, Ryu JH, Kim YS, Kim KB, Kim WS, Kim CH, Yoon JH. Treatment outcomes of juvenile nasopharyngeal angiofibroma according to surgical approach. Int J Pediatr Otorhinolaryngol 2011 Jan;75(1):69-73.

14. Hsieh ST, Guo YC, Tsai TL, Chen WY, Huang JL. Angiofibroma of the hypopharynx. J Chin Med Assoc 2004 Jul;67(7): 373-375.

15. Madana J, Yolmo D, Gopalkrishnan S, Saxena S. Extranasopharyngeal angiofibroma of the cartilaginous nasal septum: possible origin from ectopic tissue trapped during septal development. Internet J Otorhinolaryngol 2012;14(1):1-5. 